\title{
Use of a Mutilumen Catheter to Assess the Bioavailability of an Enteric- Coated High-Buffered Pancrelipase Formulation in Patients with Exocrine Pancreatic Insufficiency
}

\author{
Ahsan N. Rizwan ${ }^{1}$, Ryan Criste ${ }^{1}$, Noelia Nebot ${ }^{1}$, Kristina K. Wolf ${ }^{1}$, Kim L. R. Brouwer ${ }^{1}$ and Lisa M. Gangarosa $^{2 *}$ \\ ${ }^{1}$ Division of Pharmacotherapy and Experimental Therapeutics, UNC Eshelman School of Pharmacy, University of North Carolina at Chapel Hill, Chapel Hill, North \\ Carolina 27599-7569, USA \\ ${ }^{2}$ Department of Medicine, University of North Carolina School of Medicine, Chapel Hill, North Carolina 27599-7080, USA
}

\begin{abstract}
Treatment of exocrine pancreatic insufficiency (EPI) secondary to conditions including cystic fibrosis or chronic pancreatitis requires exogenous supplementation with a specially formulated pancreatic enzyme product (PEP). The FDA has mandated that the intestinal bioavailability of these preparations be evaluated in vivo in patients.

This pilot clinical study examined the feasibility of using a multi-lumen catheter with an occluding balloon to measure changes in intraduodenal enzyme concentrations following oral administration of a PEP.

In this two arm cross-over study, patients with mild-severe EPI were administered enteric coated (EC) highbuffered pancrelipase or placebo capsules with a liquid Lundh meal. Gastric and duodenal samples were aspirated at 15-minute intervals over 3 hours in each treatment arm. The concentrations of three pancreatic enzymes (lipase, amylase, and protease) were measured in the collected fluids. The maximum concentration $\left(\mathrm{C}_{\mathrm{max}}\right)$, and area under the duodenal enzyme concentration vs. time profile (AUC) were determined.

Comparison of enzyme concentrations between placebo and treatment phases demonstrated appreciable increases in all three enzymes in the subject with cystic fibrosis (CF+), but only a modest increase in the subject with mild-to-moderate EPI (CF-). During the EC-high-buffered pancrelipase+meal phase, the fold increase in the $\mathrm{C}_{\max }$ of lipase, amylase, and protease concentrations compared to the placebo+meal phase in subject CF- were $0.96,1.65$, and 1.64, respectively. In subject CF+, who had severe pancreatic enzyme insufficiency, the fold increase in the AUC of lipase, amylase and protease concentrations compared to the placebo+ meal phase was $66.1,15.9$, and 651 , respectively. Time to peak concentration occurred earlier during the active treatment phase. In both subjects and both treatments a peak duodenal $\mathrm{pH}$ of 8 was measured
\end{abstract}

The catheter employed in this study can be used to determine bioavailability of PEPs in severe EPI in a singleday pretreatment vs. post treatment setting (NCT00744250).

Keywords: Exocrine pancreatic insufficiency; Cystic fibrosis; Enteric coated high buffered pancrelipase; Intraduodenal; Aspiration; Catheter

Abbreviations: AUC: Area Under the Duodenal Enzyme Concentration vs. Time Profile; CLIA: Clinical Laboratory Improvement Amendments; CTRC:Clinical and Translational Research Center; EC: enteric coated; EPI: exocrine pancreatic insufficiency; FDA: Food and Drug Administration; IRB: Institutional Review Board; NDA: New Drug Appliation; PEP: Pancreatic Enzyme Products; USP: United States Pharmacopeia

\section{Introduction}

Pancreatic enzyme products (PEPs) have been in use for decades to treat patients with deficient production of pancreatic digestive enzymes, a condition known as exocrine pancreatic insufficiency (EPI). Patients suffering from EPI are unable to produce sufficient pancreatic enzymes of their own to aid digestion. In adults with EPI secondary to acute/chronic pancreatitis or pancreatic cancer, this leads to steatorrhea and weight-loss. In children with EPI secondary to cystic fibrosis or Shwachman-Diamond Syndrome, this condition can also result in malabsorption with subsequent growth and developmentrelated disorders [1].

Since most PEPs are specially formulated from porcine pancreas, considerable differences in enzyme activity are to be expected from different manufacturers and from batch to batch. The development of fibrosing colonopathy has been linked to administration of high potency (>20,000 USP units of lipase/capsule) and high dose pancreatic enzyme replacement therapy over time [2,3]. Substitution between branded and generic PEPs resulted in therapeutic failure $[4,5]$. The enzymes contained in these products are prone to inactivation if the gastrointestinal $\mathrm{pH}$ is not within the optimum $\mathrm{pH}$ range (e.g. pancreatic lipase is irreversibly inactivated in the acidic $\mathrm{pH}$ of the stomach). In one instance, failure of the enteric coating resulted in withdrawal of a product from the market [6]. Deficient bicarbonate secretion in patients with pancreatic insufficiency results in insufficient neutralization of bile acids in the upper intestine, which can increase the risk of enzyme inactivation in the duodenum if the PEP is formulated without a buffering agent. PEPs from different manufacturers are, therefore, not pharmaceutical equivalents, and inappropriate substitution in the absence of bioavailability studies may lead to overdosing, which can have serious consequences resulting in

*Corresponding author: Lisa M. Gangarosa, Department of Medicine, University of North Carolina School of Medicine, Chapel Hill, North Carolina 27599-7080, USA, Email: lisa gangarosa@med.unc.edu

Received February 03, 2011; Accepted March 28, 2011; Published March 30 2011

Citation: Rizwan AN, Criste R, Nebot N, Wolf1 KK, Brouwer KLR, et al. (2011) Use of a Mutilumen Catheter to Assess the Bioavailability of an Enteric-Coated High-Buffered Pancrelipase Formulation in Patients with Exocrine Pancreatic Insufficiency. J Bioequiv Availab 3: 026-031. doi:10.4172/jbb.1000053

Copyright: @ 2011 Rizwan AN, et al. This is an open-access article distributed under the terms of the Creative Commons Attribution License, which permits unrestricted use, distribution, and reproduction in any medium, provided the original author and source are credited. 
Citation: Rizwan AN, Criste R, Nebot N, Wolf1 KK, Brouwer KLR, et al. (2011) Use of a Mutilumen Catheter to Assess the Bioavailability of an Enteric-Coated High-Buffered Pancrelipase Formulation in Patients with Exocrine Pancreatic Insufficiency. J Bioequiv Availab 3: 026-031. doi:10.4172/jbb.1000053

hyperuricosuria, hyperuricemia, and colonic strictures [7]. Since PEPs were originally marketed before the Federal Food, Drug, and Cosmetic Act of 1938 was passed, they had been exempt from a formal FDA review and approval process. However, in 2004, the FDA required a New Drug Application (NDA) for all PEPs. In April 2006, the FDA issued Guidance for Industry on NDA requirements for PEPs. One of the requirements was determination of bioactivity/bioavailability of the exogenously administered enzymes at the site of action (i.e., the gastrointestinal tract) from aspirates collected from the stomach and duodenum.

The aim of this study was to assess the feasibility of using a specially designed multi-lumen catheter to collect gastric and duodenal samples from patients with EPI to determine the bioavailability of an enteric coated (EC) high-buffered pancrelipase (Pancrecarb). Previously, we reported the use of a multi-lumen catheter (CHOL-ect) for several applications: evaluation of drug absorption following administration in different regions of the gastrointestinal tract; measurement of the effect of pancreatico-biliary secretions and gastrointestinal transit time on drug absorption and pharmacokinetics; determination of biliary clearance of drugs in humans; and assessment of the influence of hepatic transporter modulation on hepatic exposure of drugs in humans [8-14]. The use of catheters to determine the fate of orally ingested enzymes has been described in the literature. [15] compared an EC-PEP to a conventional PEP vs. placebo using double lumen orogastric and oro-duodenal tubes; a continuous perfusion technique was employed to sample over 4 hours and 3 consecutive days (one day for each treatment) in six adult patients with pancreatic insufficiency [15]. In another study, cumulative postprandial enzyme levels were assessed in healthy volunteers and subjects with EPI receiving either placebo or an EC-PEP [16]. Samples were obtained in a similar fashion utilizing a 5-lumen catheter.

The methodology used in the present study was designed to evaluate whether meaningful increases in pancreatic enzymes could be achieved after administration of 5 capsules of an EC-buffered PEP (containing 16,000 USP Units of lipase per capsule). With the present modified catheter, we were able to perform the catheter placement in a relatively short period of time so that the two treatment arms, placebo and active treatment, could be conducted on the same study day. Data from two different subjects, one with mild-to-moderate and one with severe EPI, were compared in this study.

\section{Materials and Methods}

This study was approved by the Institutional Review Board (IRB) of the University of North Carolina at Chapel Hill. All the patients gave their informed consent. The registration number for this study on ClinicalTrials.gov is NCT00744250.

\section{Study drug}

The study drug was formulated as delayed-release microspheres (particle size range of $0.6-1.5 \mathrm{~mm}$ ) filled in clear gelatin capsules incorporating buffered ( $2.5 \mathrm{mEq}$ of bicarbonate per capsule) pancreatic enzymes (lipase, amylase, and protease) isolated from concentrated porcine pancreatic glands. The drug (now named Pertzye) was first marketed in the USA in 1995 by Digestive Care, Inc as Pancrecarb (16,000 USP units of lipase per capsule). The enzyme-containing microspheres are coated with a $\mathrm{pH}$-sensitive polymer coating to provide protection against gastric inactivation of the buffer-stabilized enzymes during gastric passage. Five EC-high-buffered pancrelipase capsules containing lipase (16,000 USP units), amylase (52,000 USP units) and protease (52,000 USP units) were administered in this study
(Table 1). Capsules were filled to $100 \%$ lipase with no overfill. Placebo consisted of white opaque gelatin capsules filled with EC microspheres. Placebo capsules contained all the excipients including the bicarbonate buffer minus the active drug substance, pancrelipase.

\section{Test meal and administration}

The study drug and placebo capsules were administered with a standardized test meal known as the Lundh meal [17-19]. The liquid Lundh meal is designed to simulate a fed state and to stimulate pancreatic secretions. The Lundh meal was prepared by the research kitchen at the UNC Clinical and Translational Research Center (CTRC) for administration with the EC-high-buffered pancrelipase and placebo capsules. It was composed of $26 \mathrm{~g}$ skim milk powder, $40 \mathrm{~g}$ dextrose, and $19 \mathrm{~g}$ corn oil. Distilled water $(290 \mathrm{~mL})$ was added to a final volume of $\sim 360 \mathrm{ml}$. The preparation was mixed thoroughly prior to administration. It was given to the subject in a cup and the subject was required to drink the whole preparation via a straw within 10 minutes.

\section{Sample collection device (the CHOL-ect multi-lumen} catheter)

The CHOL-ect multi-lumen catheter (Figures 2A and 2B) was used for gastric and duodenal aspiration. This customized polyvinyl chloride (PVC) catheter was designed by Ghibellini, Johnson, Heizer, Brouwer and co-workers in collaboration with Dentsleeve International Ltd (Mississauga, Ontario, Canada). The catheter, currently manufactured by Mui Scientific, Inc (Mississauga, Ontario, Canada), has an outer diameter of $7.1 \mathrm{~mm}$ for the first $100 \mathrm{~cm}$, and $4.6 \mathrm{~mm}$ for the remaining $28 \mathrm{~cm}$. An inflatable non-latex balloon is located at the tip with radio-opaque marker rings at three positions along the length of the catheter. This inflatable balloon is used to occlude the duodenal lumen to increase collection efficiency. The lumen of the catheter consists of eight channels for: 1) duodenal aspiration, 2) teflon-coated guidewire insertion, 3) duodenal vacuum relief, 4) stomach vacuum relief, 5) proximal duodenal saline flush, 6) distal duodenal saline flush, 7) balloon inflation, and 8) gastric aspiration [20]. The large number and the distribution of aspiration/perfusion ports along the catheter add to the versatility of the device for different applications. Prior to use, the catheters were inspected visually for any damage, tested to make sure all channels were clear and autoclaved utilizing ethylene oxide gas autoclave technique [21]. For positioning, a teflon coated guide-wire was inserted into lumen $\# 2$.

\section{Study procedure}

This was an open label, cross over, two arm (pretreatment versus post-treatment) single center study. The study involved one out-patient visit for screening, and one in-patient visit for the aspiration procedure.

Screening visit: Potential subjects were screened if they required daily exogenous enzyme supplementation with commercially available pancreatic enzymes, were $\geq 18$ years of age, were a male or nonpregnant female, confirmed the ability to swallow large capsules, and had no acute medical conditions in the last 3 months. Informed consent was obtained. During screening, subjects underwent a medical history assessment, physical exam, and clinical laboratory testing.

\begin{tabular}{|l|l|l|}
\hline & & $\begin{array}{l}\text { Theoretical concentration with a dose of 5 } \\
\text { capsules and } \mathbf{3 5 0} \mathbf{~ m L} \text { meal volume }\end{array}$ \\
\hline Lipase & 16,000 USP Units & 229 USP Units/mL \\
\hline Amylase & 52,000 USP Units & 743 USP Units $/ \mathrm{mL}$ \\
\hline Protease & 52,000 USP Units & 743 USP Units/mL \\
\hline
\end{tabular}

Table 1: Labeled potency of pancreatic enzymes in EC high-buffered pancrelipase capsules. 
Citation: Rizwan AN, Criste R, Nebot N, Wolf1 KK, Brouwer KLR, et al. (2011) Use of a Mutilumen Catheter to Assess the Bioavailability of an Enteric-Coated High-Buffered Pancrelipase Formulation in Patients with Exocrine Pancreatic Insufficiency. J Bioequiv Availab 3: 026-031. doi:10.4172/jbb.1000053

A spot fecal elastase 1 test from a stool sample was used to confirm pancreatic enzyme insufficiency in patients [22]. Subjects were selected for the study only if the spot fecal elastase 1 was $<200 \mu \mathrm{g} / \mathrm{g}$ at the time of screening [23-25].

Study visit: Eligible subjects began the study phase within one month of screening. Subjects arrived at the CTRC the evening before the study. Upon admission, the subject underwent assessment of vital signs and placement of an IV drip (0.9\% normal saline solution at $125 \mathrm{~mL} / \mathrm{hr}$ for hydration). Subjects were asked to fast after midnight. The next morning, fluoroscopic assisted placement of the catheter was performed by the team, as detailed previously [8-14]. The catheter was placed orally and the distal tip positioned in the distal duodenum. An oral anesthetic (benzocaine) was administered if requested. Following successful placement, the tube was taped to the outside of the cheek to prevent further movement of the tube down the intestine.

Aspiration procedure: Following successful catheter placement, the subject was taken to his/her room and rested in a comfortable chair in an upright position. The study was divided into two phases, a placebo+meal phase and an active treatment+meal phase, with a one-hour rest in between. In each phase, prior to administration of the capsules and liquid diet, aspiration of baseline gastric and duodenal secretions was attempted. Subsequently, subjects were asked to swallow 5 capsules administered orally along with the liquid meal (Lundh diet) within $10 \mathrm{~min}$. Gastric and duodenal fluids were aspirated continuously over $180 \mathrm{~min}$ at 15 -min intervals via the catheter. The balloon was inflated at $45 \mathrm{~min}$. After the first 180 minute phase, the balloon was deflated and the subject had a 60 -minute rest period. The internal lumen of the tube was cleaned with a saline flush. After both phases were complete, the balloon was deflated and the catheter was removed. The subject was permitted to resume his/her normal medications and discharged after a one-hour observation period.

Sample processing and enzyme assays: The volume of the sample that was aspirated during each collection interval was recorded. All aspiration samples were kept on ice during collection. Samples were aliquoted, frozen, and shipped overnight on dry ice for analysis. Samples were tested for lipase, amylase, and protease activities. All enzyme activity assays were performed in the CLIA (Clinical Laboratory Improvement Amendments) certified Gastroenterology Laboratory at Nemours Children's Hospital, Wilmington, DE. Enzyme concentration was reported as activity in USP units/mL of sample. The $\mathrm{pH}$ and protein content of the aspirates were determined and enzyme fingerprinting (data not shown) also was performed to confirm the presence of the exogenous source of enzymes.

Data analysis: The maximum enzyme concentration in each phase was determined by visual inspection of the data. The area under the duodenal enzyme concentration vs. time profile (AUC) through the last time point was determined by the linear trapezoidal method in WinNonlin version 5.0 (Pharsight Corporation, Palo Alto, CA, USA).

\section{Aspiration procedure}

Data from two subjects, a patient with cystic fibrosis and a patient without cystic fibrosis, referred to henceforth as subjects CF+ and CF-, respectively, are presented in this study. Subject characteristics and fecal elastase 1 levels are shown in Table 2. Baseline gastric secretion prior to meal administration was acidic with a $\mathrm{pH}$ of 1.9 and 2.5 for subjects $\mathrm{CF}$ - and $\mathrm{CF}+$, respectively. In both subjects, baseline duodenal samples could not be obtained at the start of the study (placebo+meal phase), presumably because of the overnight fasting. The $\mathrm{pH}$ of duodenal contents was maintained at values $>6$ for both patients during both EC-

\begin{tabular}{|l|l|l|l|l|}
\hline Patient & Age & Sex & Race & $\begin{array}{l}\text { Spot Fecal Elastase 1 } \\
(\mu \mathrm{g} / \mathrm{g} \text { stool })\end{array}$ \\
\hline CF- & 57 & F & Caucasian & 190 \\
\hline CF+ & 30 & M & Caucasian & $<15$ \\
\hline
\end{tabular}

CF- indicates subject did not have cystic fibrosis and had mild-to-moderate EPI; $\mathrm{CF}+$ indicates subject had cystic fibrosis and severe EPI; F-female, M-male; $\mu$-micro, g-gram

Table 2: Subject Demographics.

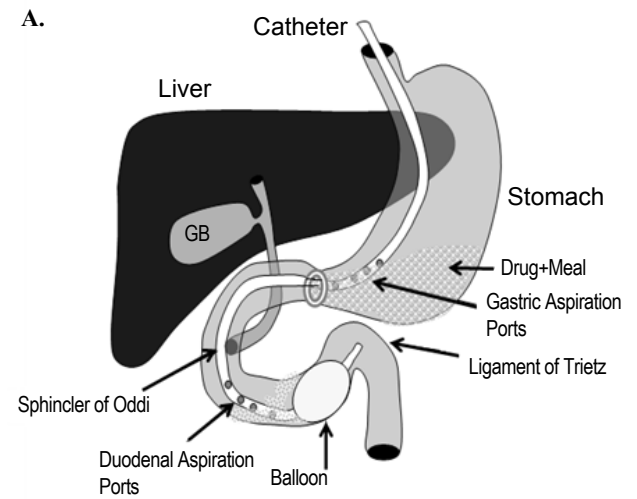

B.

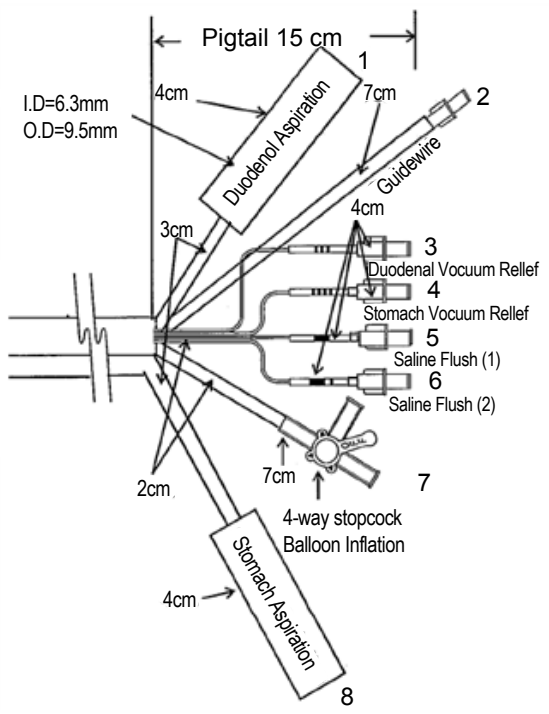

Figure 1: (A) Schematic representation of the aspiration methodology using the multi-lumen catheter. The catheter is shown in its optimal collecting position with the inflated balloon blocking the intestinal lumen and collection ports positioned to facilitate aspiration. (B) Distribution and function of the various lumens in the CHOL-ect catheter. Design copyrighted and manufactured by Mui Scientific, Mississauga, Ontario, Canada. GB- Gall Bladder, I.D- inner diameter, O.D- outer diameter.

high-buffered pancrelipase + meal and placebo+meal phases (Figure 2 and 3). Distinct spikes in duodenal $\mathrm{pH}$ were observed in both placebo and treatment phases.

The volume of the Lundh meal administered was approximately $360 \mathrm{~mL}$. In subject CF- the total volume (duodenal+gastric) collected was equal to or greater than the volume of the liquid meal in the placebo phase. In the placebo phase $443.5 \mathrm{~mL}$ of liquid was recovered; $359 \mathrm{~mL}$ was recovered in the active treatment phase. The larger total volume collected may reflect dilution with gastric/pancreato-biliary secretions and saliva. In the $\mathrm{CF}+$ subject, $262 \mathrm{~mL}$ of liquid was recovered in the placebo phase and $246 \mathrm{~mL}$ was recovered in the active treatment phase. 
Citation: Rizwan AN, Criste R, Nebot N, Wolf1 KK, Brouwer KLR, et al. (2011) Use of a Mutilumen Catheter to Assess the Bioavailability of an Enteric-Coated High-Buffered Pancrelipase Formulation in Patients with Exocrine Pancreatic Insufficiency. J Bioequiv Availab 3: 026-031. doi:10.4172/jbb.1000053

\section{Enzyme concentrations}

The enzyme concentrations and $\mathrm{pH}$ at each time point of collection for the two subjects in the two treatment arms (placebo+meal and EC-high-buffered pancrelipase+meal) are shown in Figures 2 and 3, respectively. The maximum duodenal enzyme concentration $\left(\mathrm{C}_{\max }\right)$ and the area under the duodenal enzyme concentration vs. time curve (AUC) for each enzyme in each of the treatment arms are reported in Table 3. While only a moderate increase was observed in amylase and protease for subject CF- following active treatment (Figure 2), a

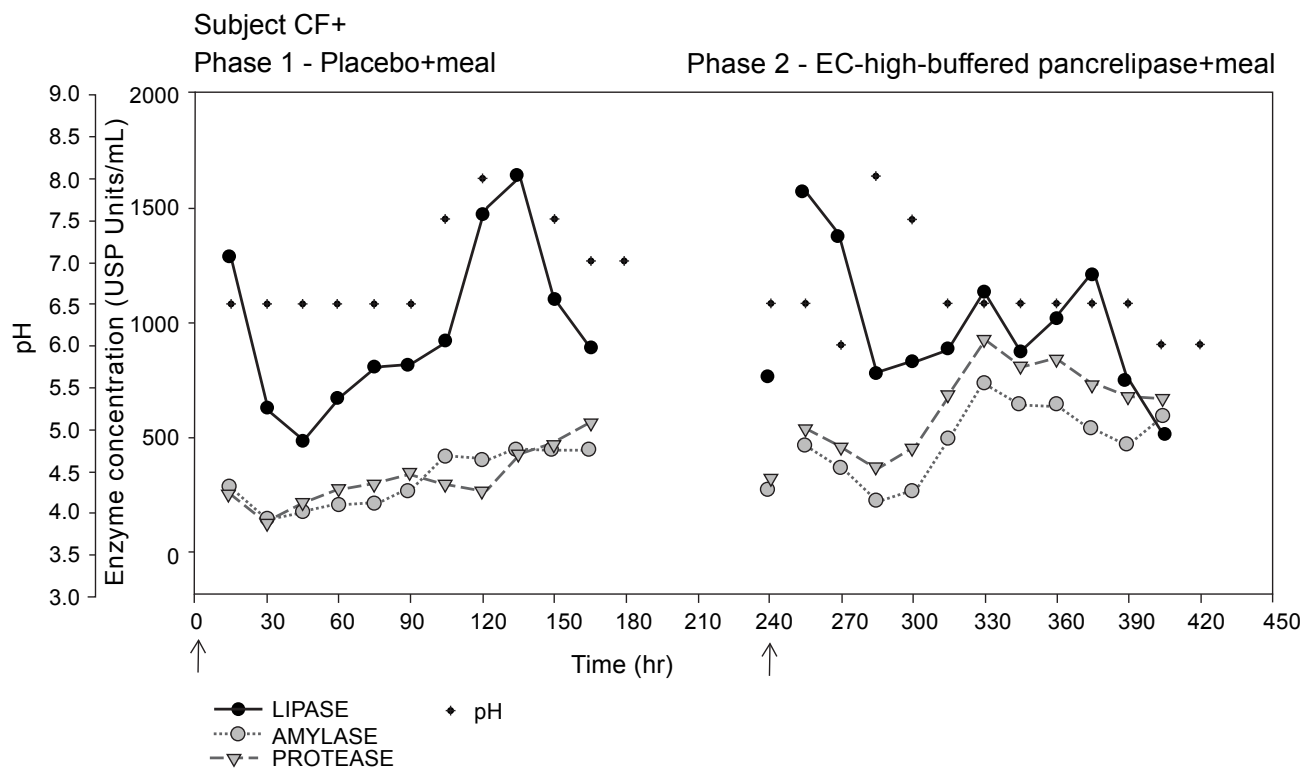

Figure 2: Duodenal enzyme concentrations and pHs in subject CF-. In Phase I (placebo+meal), the duodenal aspirate contained significant concentrations of al enzymes and the $\mathrm{pH}$ was increased due to the bicarbonate buffer content of the Placebo formulation. A steady increase in amylase and protease concentrations was observed with time. The $\mathrm{pH}$ was between 6.0 and 7.5 throughout the measurement interval. After administration of pancreatic enzymes in Phase II (EC-high-buffered pancrelipase+meal), the peak concentrations of protease and amylase were observed at 90 minutes post-dose (at 330 min in Phase II) and coincided with the peak pH of 7.5. Lipase concentration was variable, with no specific trend in relation to the $\mathrm{pH}$. Arrows indicate time when all meal and study drug had been ingested and sample collection was started. Baseline concentrations are plotted at 240 min for Phase 2.

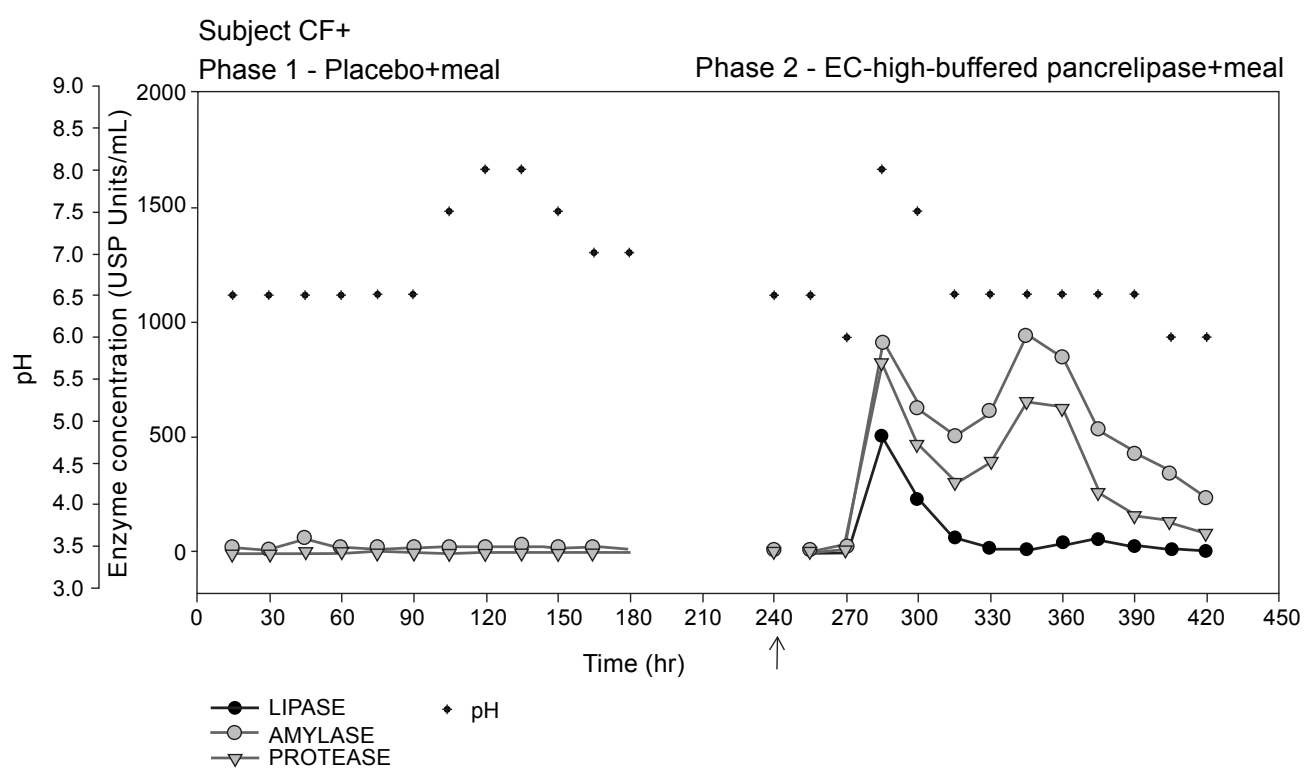

Figure 3: Duodenal enzyme concentrations and pHs in subject CF+. In Phase I (placebo+meal), the concentration of lipase and protease in the duodenal fluid were negligible, and there was a small amylase peak $45 \mathrm{~min}$ post-dose. The $\mathrm{pH}$ was 6.5 at onset, and increased to a maximum of 8.0 and then fell to a value of 7.0 due to the bicarbonate buffer content of the Placebo formulation. After administering pancreatic enzymes in Phase II (EC high-buffered pancrelipase+meal), lipase concentrations peaked at 45 min post-dose. Two peaks were observed for amylase and protease at 45 and 105 minutes post-dose. The pH increased from 6.5 at baseline to 8.0 at the first peak release of enzymes. Given the negligible background enzyme concentrations, this suggested both release of pancreatic enzymes as well as the bicarbonate buffer from the formulation in Phase II. Arrows indicate time when all meal and study drug had been ingested and sample collection was started. Baseline concentrations are plotted at $240 \mathrm{~min}$ for Phase 2. 
Citation: Rizwan AN, Criste R, Nebot N, Wolf1 KK, Brouwer KLR, et al. (2011) Use of a Mutilumen Catheter to Assess the Bioavailability of an Enteric-Coated High-Buffered Pancrelipase Formulation in Patients with Exocrine Pancreatic Insufficiency. J Bioequiv Availab 3: 026-031. doi:10.4172/jbb.1000053

\begin{tabular}{|c|c|c|c|c|c|c|c|c|c|}
\hline \multirow[b]{2}{*}{ Enzyme } & \multirow[b]{2}{*}{ ID } & \multicolumn{2}{|c|}{ EC-high-buffered pancrelipase } & \multirow[b]{2}{*}{ AUC } & \multicolumn{2}{|l|}{ Placebo } & \multirow[b]{2}{*}{ AUC } & \multicolumn{2}{|c|}{$\begin{array}{l}\text { EC-high-buffered pancrelipase/Placebo } \\
\text { ratio }\end{array}$} \\
\hline & & $\mathbf{C}_{\max }$ & $T_{\max }$ & & $\mathbf{C}_{\max }$ & $\mathbf{T}_{\max }$ & & $\mathrm{C}_{\max }$ & AUC \\
\hline & & USP Units/mL & $\min$ & USP Units*hr/mL & USP Units/mL & & USP Units*hr/mL & $\min$ & \\
\hline \multirow[t]{2}{*}{ Lipase } & CF- & 1562 & 15 & 2737 & 1629 & 135 & 2538 & 0.96 & 1.08 \\
\hline & $\mathrm{CF}+$ & 499 & 45 & 229 & 7.55 & 165 & 8.16 & 66.1 & 28.1 \\
\hline \multirow[t]{2}{*}{ Amylase } & CF- & 735 & 90 & 1308 & 446 & 135 & 803 & 1.65 & 1.63 \\
\hline & $\mathrm{CF}+$ & 942 & 105 & 1470 & 59.3 & 45 & 62.4 & 15.9 & 23.5 \\
\hline \multirow[t]{2}{*}{ Protease } & CF- & 919 & 90 & 1736 & 559 & 165 & 809 & 1.64 & 2.15 \\
\hline & $\mathrm{CF}+$ & 827 & 45 & 954 & 1.27 & 105 & 3.10 & 651 & 308 \\
\hline
\end{tabular}

Ratios of peak enzyme concentration and AUCs, active treatment compared to placebo, are shown. $C_{\text {max }}$-peak enzyme concentration; AUC $_{\text {last }}{ }^{-}$area under the duodenal enzyme concentration vs. time curve through the last measurable time point, $T_{\max }$ - time to $C_{\max }$

Table 3: Comparison of duodenal enzyme concentrations.

substantial increase in all three enzymes was observed in subject CF+ (Figure 3).

During the EC-high-buffered pancrelipase+meal phase, the fold increase in the AUC of lipase, amylase and protease concentrations compared to the placebo + meal phase in subject CF- was 1.08, 1.63 and 2.15 , respectively (Table 3 ). In subject $\mathrm{CF}+$, who had severe pancreatic enzyme insufficiency, the fold increase in the AUC of lipase, amylase and protease concentrations compared to the placebo+ meal phase was 8,24 and 308 , respectively (Table 3 )

\section{Discussion}

In the present study, we have demonstrated the feasibility of using a specially designed eight-lumen PVC catheter to assess intraduodenal pancreatic enzyme concentrations following exogenous enzyme supplementation with an EC high-buffered pancrelipase formulation. This is an important objective since the FDA now requires manufacturers to demonstrate adequate bioavailability of pancreatic enzymes from a given formulation. This requirement will aid in developing formulations with improved bioavailability. Also, knowledge of the in vivo bioavailability will ensure that appropriate doses are administered to manage EPI.

\section{Subject with mild-to-moderate pancreatic enzyme insufficiency}

Patient CF- had relatively high pancreatic enzyme concentrations in the placebo+meal phase indicating good exocrine pancreatic function. Hence, the subject may have had only mild-to-moderate EPI. Following administration of the EC-high-buffered pancrelipase+meal, an increase of approximately 2 -fold in amylase and protease concentrations was observed, while almost no increase in lipase was evident based on AUC comparisons. It is difficult to hypothesize why an additive effect was not observed in enzyme concentrations after enzyme supplementation in subject CF- (Figure 2). One possible explanation may be found in comparing the temporal changes of enzyme concentrations between the two phases. Looking at the enzyme concentration vs. time profiles for subject CF- in Figure 2, a steady rise in the concentrations of amylase and protease was evident during the placebo+meal phase. The rise to peak was markedly different in the pancrelipase+meal phase. In the active treatment phase, the peak concentrations of amylase and protease occurred at $90 \mathrm{~min}$, and then dropped off, representing drug release and decay. In the placebo phase, the peak enzyme concentrations occurred at the end of the profile possibly representing steadily rising exocrine pancreatic secretion in response to the meal (see $\mathrm{T}_{\max }$ values in Table 3).

\section{Subject with severe pancreatic enzyme insufficiency}

For subject $\mathrm{CF}+$ with severe exocrine pancreatic insufficiency, the results and interpretation of the data are more straight-forward and attributable to the treatment. In the placebo phase, subject CFhad extremely low levels of amylase, lipase and protease, even upon stimulation with the meal. Because of these low background levels, the differences between the two treatments (placebo+meal and EC-highbuffered pancrelipase+meal) could be observed very clearly (Figure 3 ). These results suggest that patients selected for intestinal bioavailability studies to assess PEPs could be stratified based on the degree of pancreatic insufficiency, and that severely deficient sub-populations should be analyzed separately. Patients with severe EPI are at the greatest risk from overdosing because of the high doses they require. Studies to demonstrate bioavailability of the PEPs in patients with cystic fibrosis would be clinically relevant. For patients with less severely compromised pancreatic function, an assay that could differentiate endogenous from exogenous pancreatic enzymes would be helpful in order to eliminate the background of endogenous pancreatic enzymes in these patients. In the present study, although we were able to confirm the presence of exogenous porcine enzymes through fingerprinting by protein SDS gel electrophoresis (data not shown), it was not possible to make a quantitative assessment of exogenously administered pancreatic enzymes only; thus, total enzymes were quantified.

\section{Physiological sources of variability}

Physiological factors such as the rate of gastric emptying, gastrointestinal $\mathrm{pH}$, and gastrointestinal motility affect study outcome and increase intersubject variability. We excluded subjects with a recent history of gastrointestinal surgery. Subjects also were asked to refrain from taking any medications that might affect gastrointestinal motility prior to the study. It is also possible that some subjects may fail to maintain duodenal $\mathrm{pH}$ above the $\mathrm{pH}$ range required for dissolution of the EC microspheres. This is especially true for subjects with cystic fibrosis where bicarbonate secretion also is impaired. Bicarbonate secretion by the pancreas helps to neutralize the acidic contents that are emptied from the stomach. Pancrecarb (Pertzye) is a preparation that contains $2.5 \mathrm{mEq}$ bicarbonate per capsule (high-buffer formulation) in order to ensure that the enzymes released from the microspheres remain highly active in a buffered microenvironment.

Furthermore, EPI itself is difficult to diagnose and characterize in terms of mild, moderate, or severe insufficiency. Most tests of pancreatic function are only accurate in advanced disease [24]. The normal pancreas secrete 1-2 L of water, bicarbonate, digestive enzymes and other proteins and minerals per day under complex regulatory mechanisms [26]. Based on the underlying cause of pancreatic 
Citation: Rizwan AN, Criste R, Nebot N, Wolf1 KK, Brouwer KLR, et al. (2011) Use of a Mutilumen Catheter to Assess the Bioavailability of an Enteric-Coated High-Buffered Pancrelipase Formulation in Patients with Exocrine Pancreatic Insufficiency. J Bioequiv Availab 3: 026-031. doi:10.4172/jbb.1000053

insufficiency, the levels of these secretions will vary considerably from one individual to another. It also has been reported that patients may be deficient in only some enzymes and not others [24]

\section{Utility of the CHOL-ect catheter}

In the present study, the CHOL-ect catheter was used to measure the in vivo dissolution and release of lipase, amylase and protease enzymes from the EC-high-buffered pancrelipase in two subjects at two extremes of pancreatic insufficiency. The Lundh diet was chosen as the test meal because it is a reliable and standard method to stimulate both exocrine and endocrine pancreatic secretions. The use of this technique to assess the bioavailability of pancreatic enzyme preparations has several advantages. Most intestinal perfusion studies require several days for completion, with multiple catheter placements; in some studies, the catheter remains in position over several days. In contrast, the CHOL-ect catheter can be positioned on the day of the study, and two arms of the study (e.g. placebo vs. treatment) can be completed on the same day in the same subject. This greatly reduces subject discomfort and improves safety. Due to the large number of lumens in the CHOL-ect catheter, multiple catheters (e.g. nasogastric) do not have to be inserted and gastric and duodenal samples can be collected via the same catheter. Using manual suction by catheter tip syringes, sufficient volumes of both gastric and duodenal fluids can be aspirated. The presence of lumens, through which vacuum relief could be provided by injecting air using a $5 \mathrm{~mL}$ syringe, aided sample collection and also relieved patient discomfort if there was build-up of gas within the gastrointestinal lumen. During the rest period between treatment phases, the lumens can be cleaned using normal saline. Deflation of the balloon during the rest period also ensures that any remaining drug/ meal from the first phase is cleared from the duodenum so that it does not interfere with measurements during the second phase.

\section{Conclusion}

This pilot study describes a novel methodology to accurately assess the in vivo intestinal bioavailability of pancreatic enzyme preparations. The study may be conducted in a crossover design with two treatment arms (placebo+meal and active treatment+meal) in order to minimize subject discomfort and reduce variability. The CHOL-ect multi-lumen catheter with an occluding balloon is amenable to the efficient collection of gastric and duodenal samples to assess changes in intraduodenal enzyme concentrations following oral administration of pancreatic enzyme preparations. With the use of an appropriate number of age and sex matched subjects to further reduce variability we believe that the methodology discussed here is an appropriate way to assess the bioavailability of PEPs in humans.

\section{Acknowledgements}

The authors gratefully acknowledge the assistance of Mikki Sandridge, Jennifer Barner, Tracy Rupp and, the CTRC staff.

\section{Statement of Interests}

The project was sponsored by Digestive Care, Inc., which developed and manufactures Pancrecarb ${ }^{\circledR}$. This project was supported in part by grant UL1RR025747 from the National Center of Research Resources, National Institutes of Health. Ahsan N. Rizwan, PhD, and Noelia Nebot, PhD, were GlaxoSmithKline sponsored Clinical Pharmacokinetics/Pharmacodynamics Fellows at the UNC Eshelman School of Pharmacy, Division of Pharmacotherapy and Experimental Therapeutics.

\section{References}

1. Ferrone M, Raimondo M, Scolapio JS (2007) Pancreatic enzyme pharmacotherapy. Pharmacotherapy 27: 910-920.

2. Smyth RL, Ashby D, O'Hea U, Burrows E, Lewis P, et al. (1995) Fibrosing colonopathy in cystic fibrosis: results of a case-control study. Lancet 346: 1247 1251.

3. Pancrecarb ${ }^{\circledR}$.Prescribing.Information (2008) Pancrecarb ${ }^{\circledR} \quad$ (pancrelipase) Delayed Relase Capsules - Bicarbonate-Buffered and Enteric-Coated Microspheres. Prescribing Information. Digestive Care Inc. 2008.

4. Hendeles L, Dorf A, Stecenko A, Weinberger M (1990) Treatment failure after substitution of generic pancrelipase capsules. Correlation with in vitro lipase activity. Jama 263: 2459-2461.

5. Hasler WL (1998) Pancreatic enzymes and colonic strictures with cystic fibrosis: a case-control study. Gastroenterology 114: 609-611.

6. Rheinstein PH (1990) Regulatory status of pancreatic enzyme preparations Jama 263: 2491-2492.

7. Whitcomb D, Pfützer R, Slivka A (1999) Alcoholic chronic pancreatitis. Curr Treat Options Gastroenterol 2: 273-282.

8. Warner PE, Brouwer KL, Hussey EK, Dukes GE, Heizer WD, et al. (1995 Sumatriptan absorption from different regions of the human gastrointestinal tract. Pharm Res 12: 138-143.

9. Reynolds KS, Song MH, Heizer WD, Burns CB, Sica DA, et al. (1998) Effect of pancreatico-biliary secretions and $\mathrm{Gl}$ transit time on the absorption and pharmacokinetic profile of ranitidine in humans. Pharm Res 15: 1281-1285.

10. Fischer JD, Song MH, Suttle AB, Heizer WD, Burns CB, et al. (2000) Comparison of zafirlukast (Accolate) absorption after oral and colonic administration in humans. Pharm Res 17: 154-159.

11. Ghibellini G, Leslie EM, Brouwer KL (2006) Methods to evaluate biliary excretion of drugs in humans: an updated review. Mol Pharm 3: 198-211.

12. Ghibellini G, Vasist LS, Hill TE, Heizer WD, Kowalsky RJ, et al. (2006) Determination of the biliary excretion of piperacillin in humans using a nove method. Br J Clin Pharmacol 62: 304-308.

13. Ghibellini G, Bridges AS, Generaux CN, Brouwer KL (2007) In vitro and in vivo determination of piperacillin metabolism in humans. Drug Metab Dispos 35 345-349.

14. Ghibellini G, Vasist LS, Leslie EM, Heizer WD, Kowalsky RJ, et al. (2007) In vitro-in vivo correlation of hepatobiliary drug clearance in humans. Clin Pharmacol Ther 81: 406-413.

15. Delchier JC, Vidon N, Saint-Marc Girardin MF, Soule JC, Moulin C, et al. (1991) Fate of orally ingested enzymes in pancreatic insufficiency: comparison of two pancreatic enzyme preparations. Aliment Pharmacol Ther 5: 365-378.

16. Guarner L, Rodriguez R, Guarner F, Malagelada JR (1993) Fate of ora enzymes in pancreatic insufficiency. Gut 34: 708-712.

17. Lundh G (1962) Pancreatic exocrine function in neoplastic and inflammatory disease; a simple and reliable new test. Gastroenterology 42: 275-280.

18. James O (1973) The Lundh test. Gut 14: 582-591.

19. Augarten A, Dubenbaum L, Yahav Y, Katznelson D, Szeinberg A, et al. (1999) Lundh meal: a single non-invasive challenge test for evaluation of exocrine and endocrine pancreatic function in cystic fibrosis patients. Int J Clin Lab Res 29 : 114-116.

20. Ghibellini G, Johnson BM, Kowalsky RJ, Heizer WD, Brouwer KL (2004) A novel method for the determination of biliary clearance in humans. AAPS $\mathrm{J} 6$ : e33.

21. Schmidt AM, Hoeprich PD (1964) Cold Sterilization of Cardiac Catheterization Equipment with Ethylene Oxide Gas. Circulation 29: 892-894.

22. Loser C, Mollgaard A, Folsch UR (1996) Faecal elastase 1: a novel, highly sensitive and specific tubeless pancreatic function test. Gut 39: 580-586.

23. Dominguez Munoz JE (2010) Diagnosis of chronic pancreatitis: Functional testing. Best Pract Res Clin Gastroenterol 24: 233-241.

24. Chowdhury RS, Forsmark CE (2003) Review article: Pancreatic function testing. Aliment Pharmacol Ther 17: 733-750.

25. De Boeck K, Weren M, Proesmans M, Kerem E (2005) Pancreatitis among patients with cystic fibrosis: correlation with pancreatic status and genotype. Pediatrics 115: 463-469.

26. Wildman REC, Medeiros DM (2000) Advanced Human Nutrition. Chapter 3 Human Digestion and Absorption. CRC Press LLC 2000: 72-73. 